Accepted for publication 24 July 2015 • First published online 29 September 2015

This article is distributed under the terms of the Creative Commons Attribution 4.0 license (http://

creativecommons.org/licenses/by/4.0/) which permits adaptation, alteration,

reproduction and distribution without further permission provided the original work is attributed. The derivative works do not need to be licensed on the same terms.

\title{
debate
}

\section{The 'good governance' of evidence in health policy}

\author{
Benjamin Hawkins, ben.hawkins@lshtm.ac.uk \\ Justin Parkhurst, justin.parkhurst@lshtm.ac.uk \\ London School of Hygiene \& Tropical Medicine, UK
}

Calls for evidence-based policy often fail to recognise the fundamentally political nature of policy making. Policy makers must identify, evaluate and utilise evidence to solve policy problems in the face of competing priorities and political agendas. Evidence should inform but cannot determine policy choices. This paper draws on theories of 'good governance' to develop a framework for analysing and evaluating processes of evidence-informed policy making. 'Good governance' requires the use of appropriate bodies of high-quality evidence to inform policy and promotes decision-making processes that are transparent, accountable and open to contestation by the pôpulations they govern.

key words evidence-informed policy $\cdot$ good governance $\cdot$ knowledge translation

To cite this article: Hawkins, B, Parkhurst, J (2016) The 'good governance' of evidence in health policy, Evidence E Policy, vol 12 no 4, 575-92, DOI:10.1332/174426415X14430058455412

\section{Introduction}

Evidence-based policy making (EBPM) remains an ideal for which many actors in the field of health policy strive. Motivated by a commitment to alleviate human suffering, some have expressed frustration at the inability of policy makers to respond to advances in scientific knowledge which they claim point to effective policy interventions (cf Lee, 2003; Garner et al, 1998; Thamlikitkul, 2006; Feldman et al, 2001). Framing the issue in these terms, critics identify two main barriers to evidence-based policy. Either research evidence does not find its way into the hands of decision makers in forms which are accessible to them, or this evidence is ignored for political or ideological reasons. Politics is thus viewed as an impediment to effective policy, which must be overcome.

Within this paradigm, the solutions offered to overcome the barriers to evidence use are more effective knowledge transfer, exchange or translation (from here on referred to collectively as knowledge translation) (cf Shaxson et al, 2012), and advocacy of EBPM as a political objective.This approach is manifested in a number of international initiatives which aim to improve the understanding, uptake, and utilisation of evidence 
for health policy, including the World Health Organization (WHO)'s Evidence Informed Policy Network (EVIPNet), the University of California, San Francisco (UCSF)'s Evidence to Policy Initiative (E2Pi), the Harvard School of Public Health's Division of Policy Translation and Leadership Development, and the European Commission backed SUPPORT Programme (SUPPORT Programme, undated).

In some contexts, efforts to address a lack of capacity in both evidence synthesis and use are important steps in improved policy outcomes. However, it has been noted that the predominant discourse of EBPM fails to take sufficient account of the inherently political nature of the policy-making process (Sanderson, 2009; Russell et al, 2008; Pawson, 2006; Barnes and Parkhurst, 2014; Morgan-Trimmer, 2014; Greenhalgh and Wieringa, 2011; Smith,2013a).Advocates of EBPM appear to assume that the right policy prescription can be derived from relevant research evidence. Non-implementation of a policy measure indicated by a particular evidence base is seen as a failure of the policy-making process to recognise or act on that evidence. The cause of these perceived failures is seen in many cases to be 'politics'. In this context, politics is equated with the zealous determination to follow politically or ideologically motivated objectives in the teeth of evidence indicating the effectiveness of alternative policies.

Against these accounts, we acknowledge and accept the fundamentally political nature of the policy process. Policy making involves complex choices between competing political priorities and policy alternatives within the limits of the available resources. Whilst evidence of the effects of a given intervention may be well established, the issue at hand - the specific problem which advocates seek to resolve - may not be identified as a political priority by policy makers. Other policy actors may advocate that the financial resources or time in the legislative programme needed to address this problem instead be devoted to other issues. Even where an issue enters onto the policy agenda, the evidence of its effectiveness may be disputed, or may need to be weighed against additional evidence of its (potentially negative) consequences in other area. This may involve considerations of its effects beyond the area of health, including the wider impact on the economy and society. Within democratic regimes at least, debates about the use of evidence in the policy-making process are inextricably linked to questions of political legitimacy and democratic accountability. Policy makers must remain cognisant of the citizens they govern, and respond to the policy priorities they identify, and their decisions must be justifiable to those same citizens. Politics then is not a barrier to evidence use, but the defining character of the environment in which evidence is used. Within this overtly political understanding of the policy-making process, empirical evidence can inform, but cannot settle, the contests between competing interests, values and ideas which lie at the heart of that process.

The idea that policy should be informed by evidence, but cannot be derived from it, raises important questions about how we should evaluate evidence use by decision makers. What constitutes a 'good' use of evidence within the policy-making process? How ought evidence be collected, interpreted and used by policy makers? How can evidence use, and the need for effective policy, be weighed against the need for popular legitimacy and accountability to those governed? In this article, we engage with these questions and offer a potential framework for guiding and evaluating evidence use by policy makers. We introduce the concept of 'good governance' of evidence to examine and evaluate the process of evidence use by policy makers. We 
argue that a 'good' use of evidence by policy makers should be judged not in terms of the substantive policy decisions reached, but rather how those policy decisions are taken and the ways in which evidence is identified, interpreted and deployed to inform those decisions. The framework we propose is designed to be used both as a tool for policy makers seeking to use evidence effectively to inform decisions and as an analytical framework for policy analysts evaluating evidence use in policy making.

\section{Evidence-based health policy}

A now extensive literature exists on EBPM within the field of health policy, and beyond.Typically 'evidence' is equated with the scientific outputs of research-focused institutions (universities, research institutes, think tanks and non-governmental organisations). It is the role of scientists and intermediary actors (for example, knowledge brokers) to assure that those in key decision-making positions can access and understand relevant evidence. A range of studies focus on the factors facilitating and impeding the transfer of evidence from its site of production to the policymaking environment (Lavis et al, 2008; Mitton et al, 2007b; Innvaer et al, 2002b; Oliver et al, 2014a).

This predominant 'two worlds' model seeks to increase the use of evidence by bridging the divide between researchers and policy makers. While there is increasing recognition that such a view presents an oversimplified account of complex, highly political policy-making processes, it has proved remarkably persistent amongst cōmmentators and practitioners. Oliver and colleagues' systematic review (2014b) note that this concentration on 'getting evidence into policy' has perpetuated a 'theoretically naive' research agenda, focusing merely on the 'uptake of research evidence'. In keeping With this, Liverani et al's (2013) systematic review found a dearth of empirical studies investigating the political and institutional factors shaping evidence utilisation in the health sector. A recent editorial in the Journal of Epidemiology and Community Health highlights the limited penetration of this message amongst scholars and practitioners in the health community (Morgan-Trimmer, 2014).

One reason for the failure to develop more nuanced, politically-informed conceptualisation of evidence use may be the epistemological challenge such an account poses to advocates of EBPM who come from a clinical or epidemiological background, in which they are trained to consider 'evidence' as fixed and absolute. Within these disciplines methodologically rigorous research identifies 'truths' about the world, on which rational policies should be based. Despite authors from Carol Weiss (1979) to Nutley and colleagues (2007) noting the variety of meanings attributed to 'evidence use' or 'research utilisation,' much of the discourse around evidence for policy making continues to frame the issue in terms of the 'barriers' preventing evidence use. This implies that evidence use is a single, decontextualised and uncontested event, in which a clear body of existing evidence can be used as the basis for policy, without engaging with the political realities of the policy-making process.

\section{Evaluating the evidence base}

Debates around the production of policy-relevant evidence have often focused on the 'hierarchy of evidence', which identifies randomised controlled trials (RCTs) as the supposed 'gold standard' of evidence (cf Padian et al, 2010; Paxton et al, 2005). 
Adherence to this conception of evidence is particularly strong in the field of health policy, given the close relationship to evidence-based medicine.An emerging literature, however, questions the appropriateness of such evidential hierarchies when addressing complex social issues (Worrall, 2010; La Caze and Colyvan, undated; Greenhalgh and Russell, 2006). Petticrew and Roberts (2003) remind us that hierarchies of evidence were specifically developed to evaluate evidence of intervention effects - which is only one of the things about which decision makers might be concerned, and may not be easily translated to evaluate certain kinds of issues or policy programmes.

Whilst this approach may be appropriate to clinical intervention trials in evidencebased medicine, policy making in its entirety cannot be reduced to debates about 'what works', or what can be shown to work within the methodological confines of the randomised controlled trial (RCT) (or of meta-analyses of multiple RCTs). At times policy makers will wish to understand the effectiveness of different intervention options, but ultimately policy-making is an 'authoritative allocation of values' (Easton, 1971) which attempts to pursue the right course of action in a given context, at a particular time, for a certain group of people and with a particular allocation of resources (Greenhalgh and Russell, 2006, 35). It is about taking and implementing political decisions, which are informed, but not dictated, by relevant bodies of research evidence. While this is apparent to policy makers and many social scientists studying these processes, within much of the health community there remains a dominant and powerful discourse calling for more evidence of 'what works' to guide policy making. The risk in this approach is that it further obscures the importance of competing values and interests in policy debates, serving to depoliticise the policy-making process in the name of methodological best practice.

The suggestion that there are technical solutions to what are inherently political problems is reminiscent of Stone's (1997) observation that policy debates are often debates about values masquerading as debates about facts. In other words, policy debates may be framed in terms of the presence or absence of evidence for a policy, or as being between evidence-based and non-evidence-based solutions to a problem. Yet each alternative may be supported by valid, relevant evidence. For example, in the UK, health advocates have campaigned consistently for a minimum unit price (MUP) for alcohol (Hawkins and Holden, 2013; Holden and Hawkins, 2012), citing evidence of the health benefits resulting from reductions in consumption (Babor et al, 2010). In contrast, opponents challenged the evidence base, citing alternative studies of the negative impacts of the policy (McCambridge et al, 2013). The UK government rejected a MUP citing an apparent lack of evidence (Browne, 2013); a decision which was criticised by public health advocates as a failure to implement an evidence-based policy measure (Gornall, 2014).

Within the framework presented here, these criticisms misapprehend the nature of the decision faced by the government. They assume that improving public health is a shared objective within the political community when, in reality, governments must weigh the health benefits achieved through alcohol pricing against a range of other political concerns (for example, the economic importance of the alcohol industry, and public acceptability of interventions in the lifestyle choices of consumers). The rhetorical importance of 'evidence' as a legitimating factor for both policy advocates and decision makers is clear. However, the justification of decisions in terms of the presence or absence of evidence obscures the fundamentally political nature of the policy decisions. 


\section{Knowledge translation and uptake}

In her seminal work, CarolWeiss (1979) presented six models of research dissemination and impact on policy: the knowledge driven, problem solving, interactive, political, tactical and enlightenment models. In the knowledge driven and problem solving models, research may spur on policy debates or be used consciously and intentionally by policy makers to reach 'evidence-based' decisions to social problems. The interactive model highlights the interactions between researchers and policy makers in identifying and developing solutions to policy issues. At the other end of the scale, the political and tactical models describe the strategic use of evidence to pursue policy objectives (for example, highlighting research findings which support a favoured policy approach) or to deflect criticism that an issue is being ignored (for example, conducting research on an issue as a means of demonstrating its importance whilst delaying substantive policy measures). Under Weiss' enlightenment model, however, it is noted that the impact of research may be more indirect, resulting from the wider diffusion of knowledge through society (see also Innvaer et al, 2002a; Ottoson, 2009; and Jones et al, 2009, for more recent discussions).

Despite recognising the multiple - often diffuse and indirect - ways in which research findings and evidence may be distributed through society and may impact on policy, much of the study of knowledge translation, and the rhetoric of policy actors, remains implicitly grounded with a rationalist framework, focusing on direct, transactional forms of policy influence. Smith (2013a) synthesises findings from five independent reviews of knowledge translation literature (Contandriopoulos et al, 2010; Innvaer et al, 2002a; Mitton et al, 2007a; Nutley et al, 2007; Walter et al, 2005), noting that the most popular recommendations to increase the use of research in policy and practice were to: ensure research is accessible; develop ongoing, collaborative relationships between researchers and policy makers; improve structural communication channels; and ensure there are sufficiently high incentives for researchers to engage in knowledge exchange. The assumption behind this is that if enough evidence arrives in the hands of key decision makers in the correct form it will resolve policy dilemmas and lead to more effective outcomes. Yet this would only be feasible where there is no contestation over the goals or desired outcomes of a policy.

Scholars in the field of interpretative policy studies have highlighted that evidence is unable to resolve policy controversies which revolve around contested and competing value systems or issue frames (Russell et al, 2008; Schön and Rein, 1994). A number of empirical examples of health issues illustrate these points.Vamos and colleagues (2008) found that the arguments for or against Human Papiloma Virus (HPV) vaccination revolved more around 'moral, religious, political, economic, and sociocultural arguments' (2008, 302) than analyses of evidence. Similarly, Parkhurst's (2012) investigation of HIV prevention policy illustrates how selection and interpretation of epidemiological evidence to support or oppose the US's President's Emergency Plan for AIDS Relief (PEPFAR) programme could be traced to differences in deep core beliefs about sexual morality. Others have explored the moral dimension of debates over harm reduction programmes for drug users (Keane, 2003; Rhodes et al, 2010). Lavis et al (2002), draw on literature from political science to identify ideas, interests, and institutions as key factors influencing the use of health services research in policy making (see also Lavis et al, 2003). Similarly, Smith (2013a) utilises both 
ideational and institutional theories to explain the use of evidence in recent UK health policy decisions.

\section{Evidence-informed policy making}

The studies cited above have led to a re-evaluation of the terms in which the current debate on evidence use in policy making is couched. The language of evidence-based policy - implying that there is a coherent, self-evident and uncontested body of research evidence which can (and should) be translated into policy measures - has given way to evidence-informed policy (see Oxman et al, 2009). This implies a shift towards a process-based, rather than outcome-based understanding of evidence use. This language implies that policy should be made in light of relevant evidence on the issues at stake - but permits recognition of the political nature of the decisionmaking process in which there are competing political priorities, often with their own evidence bases (see Barnes and Parkhurst, 2014). Policy makers will take account of a range of other political factors (for example, stakeholder interests, available resources for institutional constraints), whilst being informed by relevant bodies of evidence.

The shift towards a discourse of evidence-informed policy making (EIPM) in the health field has made only slow progress. For example, the term 'evidence-informed policy' returns only 56 results published between 2011 and 2014 in the PubMed database, whilst 'evidence-based policy' yields 211 results over the same period. Just as the health field is slowly adopting more nuanced language, however, other fields of public policy are being urged to emulate its use of hierarchies of evidence to guide decision making. The UK government has recently established a set of 'what Jworks' centres, for instance, which attempt to apply the health sector approach to intervention effectiveness evaluations to policies in areas such as crime, education, and the management of an aging population (UK Government, 2013). Similarly, in the United States, the Coalition for Evidence-Based Policy uses examples from the health policy and medical domains to advocate for greater use of evidence of 'what works' in social policy (Coalition for Evidence-Based Policy, 2015). Such efforts represent attempts to establish allegedly 'depoliticised' governance structures or processes by removing all but technical considerations of intervention effect from decision-making criteria. In contrast, the concept of EIPM emphasises the popular-democratic, rather than technocratic basis of legitimacy, in the policy-making process.

The recent contributions to the literature challenging depoliticised accounts of evidence use represent important attempts to move beyond the still-predominant EBPM model. This article aims to build on, and supplement, these insights in two ways; firstly by making explicit the political nature of the policy-making process and the consequences of this for our understanding of the role of evidence in policy making; and secondly, by developing a framework for analysing evidence use through engagement with the concept of 'governance.'As discussed above, political contestation provides the central pillar on which new understandings of evidence use in policy must lie. Yet there remains an important normative goal to ensure evidence is used effectively and appropriately. In the following section, we propose an analytical framework to guide and evaluate evidence use by policy makers. 


\section{The 'good governance' of evidence in policy-making}

Whilst it is impossible to derive policy prescriptions exclusively from research evidence, it is nonetheless important that decision makers take into account relevant bodies of evidence (for example, on the effects and effectiveness of proposed interventions) when making policy decisions. This raises questions about what the relevant bodies of evidence for that decision might be, how this is decided, and what constitutes an adequate consideration and effective use of that evidence. Framing these questions around the use of evidence as a governance issue allows further reflection on what constitutes the 'good governance' of evidence in policy-making.

There is no single definition of good governance, although the concept is widely deployed and debated, particularly within the field of international development. Various United Nations (UN) agencies use the term in differing and overlapping ways. For example, the UN Economic and Social Commission for Asia and the Pacific (2009) states that good governance has eight major characteristics: 'It is participatory, consensus oriented, accountable, transparent, responsive, effective and efficient, equitable and inclusive and follows the rule of law'. The UN Economic Commission for Africa alternatively defines good governance as implying 'participation, transparent, accountable, effective and equitable management of the public affairs' $(2013,7)$. Other definitions abound, with Grindle (2007), for instance, providing a comparison of a set of international development actors' definitions of the concept. Given the focus on both efficiency and accountability present within many of these frameworks, Rhodes has argued that the concept of good governance 'marries the new public management to the advocacy of liberal democracy' (Rhodes, 2000, 57). In other owords, it underlines the need for governments to produce not just effective responses to issues of importance to those they govern, but to put in place mechanisms through which those affected by specific policies can feed into the decision-making process and through which policy makers can be called to account for their actions.

Within the variety of definitions available, there appear to be two fundamental categories of criteria used to judge the governance of a policy environment: those which focus on the outcomes it produces (for example, efficiency, effectiveness); and those which comment on the processes by which decisions are made and implemented (for example, accountability, transparency). The first category, which emerges from the field of public administration, defines good governance in terms of the ability to achieve predetermined objectives (Grindle, 2007; Woods, 1999); the second focuses on decision making and implementation, equating good governance with processes that facilitate citizen participation and/or reflect their views, are transparent, and abide by the rule of law (Grindle, 2007; Woods, 1999).

Discourses of EBPM typically take an outcome-based approach to evidence use, equating 'good' evidence use with the adoption of a specific policy indicated by a particular body of evidence. In contrast to this, we offer a process-based account of evidence use in decision making, which merges concerns about the quality and appropriateness of the evidence informing policy decisions with an analysis of how evidence is deployed by policy makers, derived from theories of good governance. Principles of good scholarly practice exist within all disciplines, and are of central importance in evaluating the quality of research evidence, and thus the credence which should be afforded to it in policy making. Decision makers must evaluate the strength of the evidence they handle. This includes awareness by evidence users of 
the source of a given piece of evidence, including potential conflicts of interest by its producers which may affect its credibility (for example, think tanks with links to specific industries). Similarly, the established standards of systematic, rigorous, and internally valid review of evidence should guide the practices of evidence users, for example the evidence advisory bodies tasked with informing policy (cf National Health and Medical Research Council [Australia], 1999; Higgins and Green, 2011; Hagen-Zanker and Mallett, 2013). There is a need also to ensure that all appropriate, relevant bodies of evidence are identified and considered for each policy issue. This requires decision makers to consider evidence about multiple aspects of the policy debate, including those pertaining to potential externalities arising from a policy decision, as well as the core objectives of the policy. For example, whilst there may be evidence that increases in the price of alcohol or tobacco may yield population-level health benefits through reduced consumption, there may be other evidence about the wider social or economic consequences of the policy which must be considered alongside that supporting the principal health objectives of the policy.

In identifying the relevant evidence, policy makers must also set aside decontextualised claims about the strength of different forms of evidence generated by particular methodologies. These may bias decision makers towards certain types of study which may not be the most relevant or useful for understanding and evaluating certain policy issues and their proposed solutions (Mulgan, 2005). Recent debates about the over-reliance on RCTs, noted above are a case in point (Pearce and Raman, 2014). Although systematic reviews of experimental trials may be the most appropriate form of evidence to evaluate certain types of intervention effect, they do not capture other relevant concerns of policy makers such as the social desirability of a policy, the human rights implications, and equity considerations (Petticrew and Roberts, 2003). Examples of such policy issues range from the moral messages associated with drug policies, to the rights implications of quarantine or mandatory disclosure policies, to social attitudes to health problems brought about by 'lifestyle' factors (for example, smoking and alcohol consumption). In light of the multiple considerations policy makers deal with when evaluating evidence, Cookson (2005) has argued for the optimisation rather than maximisation of evidence use. We follow this assertion, arguing for the need to judge the relevance of a piece of evidence according to its appropriateness to address a specific policy problem, rather than assuming relevance is measured by a single methodological hierarchy.

Whilst policy decisions should be informed by relevant bodies of sound evidence, they must also be representative of the policy preferences expressed by citizens, and policy makers must be accountable to those governed for their decisions. The policies they adopt, the evidence they marshal to support their decisions and the interpretation of that evidence should be transparent, and thus open to contestation by policy actors and citizens. These three concepts are closely related, speak to, and have been widely discussed by scholars in the field of Science and Technology Studies (STS) concerned with the links between knowledge utilisation and democratic processes (cf Rayner, 2003; Ezrahi, 1990; Jasanoff, 2011).

As decisions over which bodies of evidence to use, and when and how to use them, embed particular values and political priorities, good governance principles require policy makers to be explicit about how evidence is deployed in the decision-making process (Pearce and Raman, 2014). Policy makers must be explicit also about the wider political, economic and practical considerations which influence decisions alongside 
evidence. This avoids attempts to 'depoliticise' the policy processes in the name of technocratic forms of decision making. Instead, policy makers should acknowledge the competing interests and political priorities at stake in any policy decision. The categories we identify to evaluate the good governance of evidence in policy-making - appropriateness, accountability, transparency and contestability - are explained further in Table 1, with examples of how these concepts might be operationalised in both policy making and analysis.

Proposing a framework for evaluating the good governance of evidence use necessarily requires a decision to privilege certain criteria over others. The choices of category made here reflect the specific context in which we are working, as well as our disciplinary backgrounds and research foci. As such, the good governance criteria put forward will be open to contestation; indeed they are designed explicitly to provoke reflection and debate on practices of evidence use and the criteria for their evaluation. However, the analytical categories proposed, we argue, allow sufficient flexibility for them to be applicable in a range of different political and cultural settings. The categories we identify for evaluating the good governance of evidence exist at both what Heidegger (1962) terms the ontological and the ontic level (see also Howarth, 2000). At the ontological levels, they point to the need to evaluate evidence use in terms of a specific set of criteria associated with the appropriateness of the evidence used, the process through which it is deployed, and the accountability of policy makers to those affected by the decisions taken. The specific, 'ontic' content, we suggest, miust be appropriate to the circumstances and settings in which policy debates, or the attempts to evaluate them, occur. This will vary across space and time, and the ontological categories identified will be filled out with different propositional content in different contexts. These categories must therefore be applied to the specific cases in a way that is thus analogous to Wittgenstein's (1953) account of 'applying a rule'. In other words, each will need to be explicated and defined in the specific contexts in which they are deployed. For example, the ways in which accountability is defined, or social concerns addressed, must be tailored to local contexts and decision-making structures.

In defining and applying good governance criteria, we must take account of the political context and the policy issue in question. This requires reflexivity both on the part of practitioners in using evidence, and scholars in evaluating these practices. Making explicit the relevant considerations in a policy decision can serve as an important first step in identifying which bodies of evidence are relevant to the decision at hand. Proposing analytical categories based on principles of appropriateness, accountability, transparency and contestability to those governed, we argue, allows sufficient flexibility for them to be applicable in a range of settings.

\section{Institutionalising the good governance of evidence}

As highlighted above, the limitations of the EBPM have been acknowledged by some scholars, yet progress towards more nuanced understandings of evidence use in policy making has been limited. The concept of the good governance of evidence attempts to accelerate this process by reiterating the political nature of policy making and providing an analytical framework for the evaluation of evidence use by decision makers within this context. It combines the desire of the health sciences for evidentiary validity with the recognition of the contested nature of the policy-making process 
Table 1: Key criteria of the good governance of evidence

\section{Concept}

Appropriateness

Accountability
Definition and explanation

The selection of evidence determined by the policy issue at hand and the requirements of the decision to be taken. Different types of evidence will be appropriate for different issues and types of decision. Evaluation of evidence selection requires an explicit statement of decision criteria by policy makers.

Judgements about the quality of evidence to be based on established methodologic principles pertaining to the type of research undertaken (for example, qualitative interviews versus clinical trials) and data generated.

Accountability systems would differ between evidence advisory bodies (EABs) and evidence users. In both cases, however, there should be clear links back to the public to ensure principles of democratic accountability are maintained. As highlighted above, the need for accountability must be balanced against the need for independence in evaluating the quality and appropriateness of evidence.

\section{Examples}

The approach is analogous to the methods of MultiCriteria Decision Analysis (Croskerry et al, 2013), which typically require an initial statement of all relevant decision criteria and an attempt to weigh, or prioritise, different considerations in the policy decision.

Application of evidence quality criteria, appropriate to the type of research being considered. For example, if intervention effect is a concern, hierarches such as those provided by the GRADE criteria or others may be most relevant (Guyatt et al, 2008). Alternatively, concerns over cost implications may require the use of economic models with their own quality criteria. Similarly, political concerns over public acceptability may instead require evidence provided from surveys judged by their own criteria of rigour (for example, appropriate sample size and representation).

In combination this involves taking steps to ensure that one has the right criteria for evaluating the evidence used, as well as the right evidence for the particular policy problem being addressed.

A wide range of managerial and oversight arrangements are possible.

For EABs, rules and structures must be established to connect them to public representatives, whilst maintaining their professional autonomy. Formal constitutions, with specific procedures in place for their amendment, are one way this may be achieved (cf the NICE Charter (NICE, 2013)in the UK which explicitly addresses many of these issues).

Constitutions for EABs are mandated by political actors, and thus indirectly by the citizens they represent. They define roles and responsibilities and thus ensure that these bodies can pursue their objectives within the parameters of their constitution without fear of punishment or retribution.

At the same time they create oversight mechanisms to ensure EABs fulfil their tasks adequately and do not overstep their mandate. In extremis, constitutions may be amended to reflect emerging needs or shifting public priorities, but with a higher threshold for change than simple laws.

Other decision makers who utilise evidence (ministers, civil servants, government agencies), should also be accountable to the public to ensure that those decisions promote public interests. There will be differences in how direct the accountability may be - for example, heads of agencies may be appointed by government ministers and held to account by legislative procedures in differing ways. In the case of government agencies the constitutional approach may also apply. 
Transparency

\section{Contestability Deriving from the basic} scientific principles of making ideas subject to open questioning through publication and peer review, mechanisms must be established to challenge the evidence used to inform a policy decision, that is, to question the appropriateness of the evidence used as defined above.
Examples through which transparency can be achieved include:

Public access to decisions or minutes of meetings;

Scrutiny by academics, NGOs and the media;

Freedom of information rules.

Appeals procedures over the decisions of regulatory agencies;

Public consultations and stakeholder events at different stages of the policy-making process;

Public debate and advocacy.

and the need for transparency and accountability. However, in order to operationalise the good governance of evidence, there is a need to put in place structures which embed the good governance principles outlined above.

Policy decisions, and the use of evidence within policy making, occur within institutional settings and broader normative and cultural frameworks. Once formal institutions are established they can be hard to change, due to the bureaucratic inertia of staff and the path dependency of structures in place (Wilsford, 1994). Informal processes and norms can become similarly entrenched in decision-making processes if their operation leads to widespread social and bureaucratic acceptance (Peters, 2005). As such, principles relating to the good governance of evidence may also be institutionalised in both formal and informal decision-making structures.

Whilst much of the knowledge translation literature discussed above focuses on the role of key individuals in the policy process and the importance of personal relationships between scientists and policy makers, these relationships are often unsustainable in the long term. Even assuming the ability of well-placed individuals to ensure evidence use at certain times and in certain policy domains, the constant movement of officials between policy domains and roles leads to a lack of institutional memory regarding evidence use and requires a constantly evolving process of relationship building (cf Smith, 2013b; Flitcroft et al, 2011; Hunsmann, 2012 ). Similarly, the reliance on key individuals means that evidence use will vary greatly between health issues (as well as across policy domains) depending on the dispositions of key policy makers in 
each area, and the ability of scholars and knowledge brokers to gain access to them. Knowledge brokers may offer only one form of evidence to policy makers or present only evidence which support a particular course of action. Health researchers, for example, are likely to frame issues around the health impacts of a measure, and may set aside externalities or wider consequences of the policy (and thus the evidence of these). It is thus an ad hoc rather than a scalable model of evidence use. There is therefore a need to develop institutional structures that establish and maintain good governance practices in evidence use, independent of the particular individuals within the policy process who may advocate the use of particular pieces of evidence. Attempts to improve processes of evidence use in decision making which eschew this institutional component risk undermining both their effectiveness and sustainability.

The work of groups like EVIPNet has focused on supporting agencies (or 'platforms') rather than merely training individuals (cf Cheung et al, 2011; Lavis and Panisset, 2010). These are important steps which could further be developed with the more explicit governance focus outlined here. Processes of institutionalisation must look to establish not only the rules dictating good practices of evidence review; they must also address governance structures and bureaucratic linkages to determine how they serve to inform political decision makers who should remain accountable to local populations. Current conceptualisations of evidence-based, and even evidenceinformed, policy demonstrate only limited engagement with these issues.

The specific form of the institutional structures put in place will be context specific. Different political systems and cultures will emphasise accountability, contestability, autonomy, independence, and transparency in different ways. Transparency, for example, can be established in a range of ways, including freedom of information (FOI) legislation, publication of meeting proceedings, and media scrutiny, all of which differ greatly between polities. For example, FOI laws at the EU level are more extensive than in many member states, yet the minutes of Council meetings are not published. Accountability to the public may also be achieved through different, locally determined means. For example, in the UK the National Health Service has introduced citizens' juries, and the National Institute of Health and Care Excellence (NICE) has undertaken public consultations on social values (Abelson et al, 2013); while in Brazil efforts were made to institutionalise the 'right to health' through the 1988 Citizens Constitution and subsequent efforts to build local health councils to increase participation of marginalised populations (Coelho, 2013; see Abelson et al (2013) for a review and mapping of examples of deliberative strategies across the health sector). Legislation and rules can also be directly developed to govern the use of evidence in decision making, as seen in Mexico's case of legally mandating evaluations of key social interventions (Castro et al, 2009), or the WHO's development of formal guidelines for health policy guideline development (WHO, 2003). In each example, the measures implemented reflect the realities of the governance situation at the specific place and time. Despite the specific institutional arrangements which emerge, the core principles remain that evidence is an important part of the decisionmaking process, that no single body of evidence can dictate a policy decision, and that evidence bodies do not replace decision makers in their roles as the legitimate representatives of their citizenry. 


\section{Conclusions and implications}

This paper builds on the now extensive literature on knowledge translation and evidence use in the policy-making process. We eschew the narrow, reductionist conceptions of evidence-based policy making, which continue to dominate the field of health policy and risk taking root in social policy discourse more broadly. Our aim is to bring together the important concerns at the core EBPM movement with a more nuanced conception of evidence-informed policy making. Our starting point is an explicit recognition that policy making is an inherently political process which involves competing calls for the attention of policy makers, and for the finite resources that they have at their disposal. Policy decisions involve complex political choices which reflect competing norms, values and interests, and may involve relevant bodies of evidence at each stage. As such, a process-oriented account of the governance of evidence, rather than an outcome-oriented approach, is required to judge what constitutes a 'good' evidence use in policy making.

The fundamentally political nature of policy making is often missed by calls for evidence-based policy, which neglect the fact that there are multiple, and often competing, bodies of potentially relevant evidence to which policy makers have recourse in identifying policy priorities and taking decisions. Policy advocates pursuing different political agendas couch their arguments in terms of evidence-based policy, highlighting the forms of evidence which support their particular issue framing and the course of action they advocate. What are often presented as arguments about evidence are often actually contests between competing agendas and political priorities. Scholars have noted that the existence of competing policy frames (Schön and Rein, 1994) makes appeals to evidence alone ineffective in resolving policy controversies. The rejection of a particular policy or intervention, despite evidence of its effectiveness, may not be because that evidence has been ignored, but because other policy issues or outcomes have been prioritised. This distinction is important, but often missed, in the current thinking on EBPM. The decision not to adopt the measure does not invalidate the evidence of the measure's effectiveness, nor the gravity of the problem, but underlines that policy decisions, made in the light of multiple bodies of relevant evidence, are the consequence of a complex range of political factors.

The appeal to scientific evidence is a powerful and persuasive rationale for policy decisions, reflecting wider moves towards technocratic forms of decision making (Lewis, 2003). It is a justification for both government action and inaction on policy problems. Laying bare the fundamentally political nature of the policy-making process removes the ability of decision makers to abdicate responsibility for their decisions. Instead, it forces them to explain and justify their actions to those affected by them, thus reinforcing transparency and accountability in the policy process. It is important to recast the term politics to shed it of the negative connotations it has in discourses of EBPM. Understood in this way, politics is not the barrier to evidence use, but the defining condition of the policy-making process in which evidence use occurs. Far from undermining the drive for good policy which underlies the EBPM movement, embracing the political nature of this process is the key to facilitating effective evidence use by policy makers and institutionalising mechanisms to ensure effective evidence use.

The concept of good governance employed in this article provides a conceptual framework for evaluating evidence use in policy making. The good governance 
approach to evidence use recognises the importance of maintaining democratic principles within processes of evidence utilisation, including issues of accountability, transparency and contestability, while acknowledging the need for standards of good evidentiary practice in the identification, interpretation and use of evidence. The good governance principles must be institutionalised and specific structures put in place to embed these principles. We recognise that the meaning which these categories have for the relevant policy actors will vary across policy issues, time and space. As such, they need to be applied to the specific context and recast in terms of the local meanings they obtain in different settings. We aim here to foster debate around what constitutes the good governance of evidence, with a conceptualisation that combines principles of scientific best practice with those of democratic representation. This, it is hoped, will lead to further analytical insight or refinement amongst scholars and more effective decision making by policy actors.

\section{Acknowledgements}

This work has developed as part of the Getting Research into Policy in Health (GRIPHealth) project, supported by a grant from the European Research Council (Project ID\#282118).

\section{References}

Abelson, J, Blacksher, EA, Li, KK, Boesveld, SE, Goold, SD, 2013, Public deliberation in health policy and bioethics: Mapping an emerging, interdisciplinary field, Public Deliberation 9, 5

Babor, TF, Caetano, R, Casswell, S, Edwards, G, Giesbrecht, N, Graham, K, Grube, JW, Hill, L, Holder, H, Homel, R, Livingston, M, Osterberg, E, Rehm, J, Room, R, Rossow, I, 2010, Alcohol: No ordinary commodity: Research and public policy, Oxford: Oxford University Press

Barnes, A, Parkhurst, JO, 2014, Can global health policy be depoliticised? A critique of global calls for evidence-based policy, in Yamey, G, Brown, G (eds), Handbook of global health policy, Hoboken, NJ: Wiley-Blackwell

Browne, J, 2013, Government's response to the alcohol strategy consultation, www. gov.uk/government/speeches/governments-response-to-the-alcohol-strategyconsultation

Castro, M F, Lopez-Acevedo, G, Busjeet, GB, Ordonez, XF, 2009, Mexico's MEE system: Scaling up from the sectoral to the national level, Washington, DC: World Bank

Cheung, A, Lavis, J, Hamandi, A, El-Jardali, F, Sachs, J, Sewankambo, N, KnowledgeTranslation Platform Evaluation Team, 2011, Climate for evidence-informed health systems: A print media analysis in 44 low- and middle-income countries that host knowledge-translation platforms, Health Research Policy and Systems 9, 7

Coalition For Evidence-Based Policy, 2015, Our Mission, http://coalition4evidence. org

Coelho,VSP, 2013, What did we learn about citizen involvement in the health policy process: Lessons from Brazil, Public Deliberation 9, 9

Contandriopoulos, D, Lemire, M, Denis, J-L, Tremblay, É, 2010, Knowledge exchange processes in organizations and policy arenas: A narrative systematic review of the literature, Milbank Quarterly 88, 444-83

Cookson, R, 2005, Evidence-based policy making in health care:What it is and what it isn't, Health Services Research \& Policy 10, 118-21 
Croskerry, P, Singhal, G, Mamede, S, 2013, Cognitive debiasing 1: Origins of bias and theory of debiasing, BMJ Quality \& Safety 22, ii58-ii64

Easton, D, 1971, The political system: An inquiry into the state of political science, New York: Alfred A Knopf

Ezrahi,Y,1990, The descent of Icarus: Science and the transformation of contemporary democracy, Cambridge, MA: Harvard University Press

Feldman, PH, Nadash, P, Gursen, M, 2001, Improving communication between researchers and policy makers in long-term care: Or, researchers are from Mars; policy makers are from Venus, Gerontologist 41, 312-21

Flitcroft, K, Gillespie, J, Salkeld, G, Carter, S, Trevena, L, 2011, Getting evidence into policy: The need for deliberative strategies?, Social Science \& Medicine 72, 1039-46

Garner, P, Kale, R, Dickson, R, Dans, T, Salinas, R, 1998, Getting research findings into practice: Implementing research findings in developing countries, BMJ 317, 531-5

Gornall, J, 2014, Under the influence, BMJ 348, f7646

Greenhalgh, T, Russell, J, 2006 Reframing evidence synthesis as rhetorical action in the policy making drama, Healthcare policy = Politiques de santé, 1, 34-42

Greenhalgh, T, Wieringa, S, 2011, Is it time to drop the 'knowledge translation' metaphor? A critical literature review, Royal Society of Medicine 104, 501-09

Grindle, MS, 2007, Good enough governance revisited, Development Policy Review $25,533-74$

Guyatt, GH, Oxman, AD, Vist, GE, Kunz, R, Falck-Ytter, Y, Alonso-Coello, P, Schünemann, HJ, 2008, GRADE: An emerging consensus on rating quality of evidence and strength of recommendations, BMJ 336, 924-6

Hagen-Zanker, J, Mallett, R, 2013, How to do a rigorous, evidence-focused literature review in international development: A guidance note, London: Overseas Development Institute Fawkins, B, Holden, C, 2013, Framing the alcohol policy debate: Industry actors and the regulation of the UK beverage alcohol market, Critical Policy Studies 7, 1, 53-71 Heidegger, M, 1962, Being and time, Oxford: Basil Blackwell

Higgins, JP, Green, S, 2011, Cochrane handbook for systematic reviews of interventions, version 5.1.0, Cochrane Collaboration

Holden, C, Hawkins, B, 2012, 'Whisky gloss': The alcohol industry, devolution and policy communities in Scotland, Public Policy and Administration 28, 3, 253-273

Howarth, D, 2000, Discourse concepts in the social sciences, Buckingham: Open University Press

Hunsmann, M, 2012, Limits to evidence-based health policymaking: Policy hurdles to structural HIV prevention in Tanzania, Social Science \& Medicine 74, 10,1477-1485

Innvaer, S,Vist, G,Trommald, M, Oxman, A, 2002a, Health policy-makers' perceptions of their use of evidence: A systematic review, Health Services Research \& Policy 7 , 239-44

Jasanoff, S, 2011, Constitutional moments in governing science and technology, Science E Engineering Ethics 17, 621-38

Jones, N, Datta, A, Jones, H, 2009, Knowledge, policy and power: Six dimensions of the knowledge-development policy interface, London: Overseas Development Institute

Keane, H, 2003, Critiques of harm reduction, morality and the promise of human rights, International Journal of Drug Policy 14, 227-32

La Caze, A, Colyvan, M, (unpublished), Evidence-based policy: Promises and challenges, www.colyvan.com/papers/ebp.pdf 
Lavis, JN, Oxman, AD, Moynihan, R, Paulsen, EJ, 2008, Evidence-informed health policy 1: Synthesis of findings from a multi-method study of organizations that support the use of research evidence, Implementation Science 3, 53

Lavis, JN, Panisset, U, 2010, EVIPNet: Africa's first series of policy briefs to support evidence-informed policymaking, International Journal of Technology Assessment in Health Care 26, 229-32

Lavis, JN, Robertson, D, Woodside, JM, Mcleod, CB, Abelson, J, 2003, How can research organizations more effectively transfer research knowledge to decision makers? Milbank Quarterly 81, 2, 221-48

Lavis, JN, Ross, SE, Hurley,JE, Hohenadel,JM, Stoddart, GL, Woodward, CA, Abelson, J, 2002, Examining the role of health services research in public policymaking, Milbank Quarterly 80, 125-54

Lee, JW, 2003, Science and the health of the poor, Bulletin of the World Health Organisation 81, 473

Lewis, JM, 2003, Evidence-based policy: A technocratic wish in a political world, in Lin,V, Gibson, B (eds), Evidence-based health policy: Problems and possibilities, Oxford: Oxford University Press

Liverani, M, Hawkins, B, Parkhurst, JO, 2013, Political and institutional influences on the use of evidence in public health policy:A systematic review, PloS One 8, e77404

McCambridge, J, Hawkins, B, Holden, C, 2013, Industry use of evidence to influence alcohol policy: A case study of submissions to the 2008 Scottish government consultation, PLoS Medicine 10, 4

Mitton, C, Adair, CE, Mckenzie, E, Patten, SB, Perry, BW, 2007a, Knowledge transfer and exchange: Review and synthesis of the literature, Milbank Quarterly 85, 729-68

Morgan-Trimmer, S, 2014, Policy is political; our ideas about knowledge translation must be too, Epidemiology and Community Health 68, 1010-1011

Mulgan, G, 2005, Government, knowledge and the business of policy making: The potential and limits of evidence-based policy, Evidence \& Policy 1, 215-26

National Health And Medical Research Council [Australia], 1999, How to review the evidence: Systematic identification and review of the scientific literature, Canberra: Commonwealth of Australia

NICE (National Institute for Health and Care Excellence), 2013, NICE Charter, www. nice.org.uk/Media/Default/About/Who-we-are/NICE_Charter.pdf

Nutley, SM, Walter, I, Davies, HTO, 2007, Using evidence: How research can inform public services, Bristol: Policy Press

Oliver, K, Innvaer, S, Lorenc, T, Woodman, J, Thomas, J, 2014a, A systematic review of barriers to and facilitators of the use of evidence by policymakers, BMC Health Services Research 14, 2

Oliver, K, Lorenc, T \& Innvaer, S, 2014b, New directions in evidence-based policy research:A critical analysis of the literature, Health Research Policy and Systems 12, 34

Ottoson, JM, 2009, Knowledge-for-action theories in evaluation: Knowledge utilization, diffusion, implementation, transfer, and translation, New Directions for Evaluation 124, 7-20

Oxman, AD, Lavis, JN, Lewin, S, Fretheim, A, 2009, SUPPORT Tools for evidenceinformed health policymaking (STP) 1:What is evidence-informed policymaking?, Health Research Policy and Systems 7, S1

Padian, NS, Mccoy, SI, Balkus, JE, Wasserheit, JN, 2010, Weighing the gold in the gold standard: Challenges in HIV prevention research, AIDS 24, 621-35 
Parkhurst, JO, 2012, Framing, ideology and evidence: Uganda's HIV success and the development of PEPFAR's 'ABC' policy for HIV prevention, Evidence \& Policy 8, 19-38

Pawson, R, 2006, Evidence-based policy: A realist perspective, London: Sage

Paxton,A, Maine, D, Freedman, L, Lobis, S, 2005, The evidence for emergency obstetric care, International Journal of Gynecology and Obstetrics 88, 181-93

Pearce, W, Raman, S, 2014, The new randomised controlled trials (RCT) movement in public policy: Challenges of epistemic governance, Policy Sciences 47, 387-402

Peters, G, 2005, Institutional theory in political science, London: Continuum

Petticrew, M, Roberts, H, 2003, Evidence, hierarchies, and typologies: Horses for courses, Epidemiology and Community Health 57, 527-9

Rayner, S 2003, Democracy in the age of assessment: Reflections on the roles of expertise and democracy in public-sector decision making, Science and Public Policy 30, 163-70

Rhodes, RA, 2000, Governance and public administration, in Pierre, J (ed), Debating governance: Authority steering and democracy, Oxford: Oxford University Press

Rhodes, T, Sarang, A, Vickerman, P, Hickman, M, 2010, Policy resistance to harm reduction for drug users and potential effect of change, BMJ 341

Russell, J, Greenhalgh, T, Byrne, E, McDonnell, J, 2008, Recognizing rhetoric in health care policy analysis, Health Services Research E Policy 13, 40-46

Sanderson, I, 2009, Intelligent policy making for a complex world: Pragmatism, sevidence and learning, Political Studies 57, 699-719

Schön, DA, Rein, M, 1994, Frame reflection: Toward the resolution of intractable policy controversies, New York: Basic Books

Shaxson, L, Bielak, A, Ahmed, I, Brien, D, Conant, B, Middleton, A, Fisher, C, Gwyn, E, Klerkx, L, 2012, Expanding our understanding of K (KT, KE, KTT, KMb, KB, KM, etc), Hamilton, Ontario: United Nations University, Institute for Water, Environment and Health

Smith, K, 2013a, Beyond evidence based policy in public health: The interplay of ideas, London: Palgrave Macmillan

Smith, K, 2013b, Institutional filters:The translation and re-circulation of ideas about health inequalities within policy, Policy \& Politics 41, 81-100

Stone, DA, 1997, Policy paradox: The art of political decision making, New York: WW Norton

SUPPORT programme, undated, Executive summary, Oslo: Nasjonalt kunnskapssenter for helsetjenesten, www.kunnskapssenteret.no/en/publications/support-tools-forevidence-informed-health-policymaking-stp?vis=sammendrag

Thamlikitkul, V, 2006, Bridging the gap between knowledge and action for health: Case studies, Bulletin of the World Health Organization 84, 603-07

UK Government, 2013, What Works: Evidence centres for social policy, London: UK Cabinet Office

United Nations Economic and Social Commission for Asia and the Pacific, 2009, What is good governance?, www.unescap.org/pdd/prs/ProjectActivities/Ongoing/ gg/governance.asp

United Nations Economic Commission for Africa, Governance and Public Administration Division (GPAD), 2013, The role of parliament in promoting good governance, Addis Ababa: United Nations ECA 
Vamos, CA, Mcdermott, RJ, Daley, EM, 2008, The HPV vaccine: Framing the arguments FOR and AGAINST mandatory vaccination of all middle school girls, School Health 78, 302-09

Walter, I, Nutley, S, Davies, H, 2005, What works to promote evidence-based practice? A cross-sector review, Evidence \& Policy 1, 335-64

Weiss, CH, 1979, The many meanings of research utilization, Public Administration Review 39, 426-31

WHO (World Health Organization), 2003, WHO guidelines, Geneva: WHO

Wilsford, D, 1994, Path dependency, or why history makes it difficult but not impossible to reform health care systems in a big way, Public Policy 14, 251-83

Wittgenstein, L 1953, Philosophical investigations, Oxford: Basil Blackwood

Woods, N, 1999, Good governance in international organizations, Global Governance $5,39-61$

Worrall,J, 2010, Evidence: Philosophy of science meets medicine, Evaluation in Clinical Practice 16, 356-62 